\title{
Análise Retórica em Manoel Dias de Oliveira: Exemplos de Figuras Retórico-Musicais
}

Rhetorical Analysis in Manoel Dias de Oliveira: Examples of Musical-Rhetorical Figures

Eliel Almeida Soares ${ }^{1} \mathrm{e}$ Diósnio Machado Neto ${ }^{2}$ 


\section{DAPesquisa}

\section{Resumo}

Ao enunciar seu discurso o orador serve-se da retórica para fundamentar sua tese, cujo propósito visa convencer e atrair a atenção do público, evidenciando, desse modo, sua habilidade em empregar a linguagem para mover os afetos dos ouvintes. Assim como os mestres da oratória, muitos compositores do barroco e primórdios do classicismo tanto na Europa quanto no Brasil colonial, encontraram na arte da eloquência o embasamento necessário para que suas obras fossem expostas com consistência, segurança e eficácia. Por esse motivo, o presente artigo expõe o pensamento musical de $\mathrm{Ma}$ noel Dias de Oliveira através da utilização de figuras retóricas em suas composições. Para tanto, utilizamos como metodologia ferramentas analíticas necessárias à compreensão da linguagem retórica do autor a serviço da eloquência e persuasão tais como: análises de figuras retórico-musicais associadas ao texto sacro, harmonia e distribuição do discurso musical. Mesmo a pesquisa estando em estágio inicial, obtiveram-se alguns resultados os quais serão apresentados ao longo do trabalho.

Palavras-Chave: : Análise; Figuras Retóricas; Manoel Dias de Oliveira; Música Colonial Brasileira.

\section{Abstract}

When the speaker states his speech, rhetoric is used to support his thesis in order to convince and attract the attention of the audience, showing the speaker ability to use the language to move the affections of the listener. As the masters of oratory, many composers of the Baroque and early Classicism in Europe and in Colonial Brazil, found in the art of eloquence the base needed for their work to be exposed with consistency, security and efficacy. And for this reason, the article presents the musical thought of Manoel Dias de Oliveira by using rhetorical figures in his compositions. Therefore, it was used analytical tools necessary to understand the author's rhetorical language in the service of eloquence and persuasion, such as: analysis of musical-rhetorical figures associated with sacred texts, harmony and distribution of musical discourse. Although the survey is in the beginning, we have obtained some results which will be exposed in the course of work.

Keywords: Analysis; Rhetorical Figures; Manoel Dias de Oliveira; Brazilian Colonial Music. 


\section{Introdução}

Essencial para a elaboração e produção de um discurso, a retórica é o instrumento de persuasão que visa convencer o público através do uso de artifícios linguísticos (ABBAGNANO, 2007, p.856). Em outras palavras, o objetivo derradeiro da arte da eloquência é auxiliar o orador na adesão dos ouvintes à tese apresentada, evidenciando, dessa forma, sua habilidade em empregar a linguagem para mover os afetos dos ouvintes (GUIMARÃES, 2004, p.145). Para tanto, diversos recursos são utilizados, por exemplo, metáforas, analogias, alegorias e figuras retóricas, os quais se observam desde a Antiguidade, onde muitos pensadores estabeleciam relações de conceitos cognoscíveis entre $\mathrm{si}^{3}$ (SOARES; MACHADO NETO, NOVAES, 2012, p.301).

Concomitante a essa prática, na música barroca e no princípio do classicismo, vários tratadistas, pesquisadores e compositores tais como Gallus Dressler (15331589), Johannes Nucius (1556-1620), Joachim Burmeister (1564-1629), Claudio Giovanni Antonio Monteverdi (1567-1643), Heinrich Schütz (1585-1672), Athanasius Kircher (1601-1680), Dietrich Buxtehude (1637-1707), Alessandro Scarlatti (1660-1725), Antônio Vivaldi (1678-1741), Johann Mattheson (1681-1764), Johann Gottfried Walther (1684-1748), Johann Sebastian Bach (1685-1750), Carl Philipp Emanuel Bach (1714-1788), Johann Nikolaus Forkel (1749-1818), só para citar alguns, adotaram os mesmos mecanismos retóricos, com o propósito de clarificar a significação dos enunciados musicais $^{4}$ (SOARES; MACHADO NETO; NOVAES, 2012, p.472):

A partir da fase inicial do barroco, quando as cadências exigidas pela retórica musical, com fins expressivos, tornaram-se frequentes, um número significativo de teóricos, tomaram emprestada a terminologia das figuras da retórica clássica, tendo em vista as tradicionais (ainda que genéricas) afinidades entre a música e a retórica, para explicar de forma racional as licenças praticadas pelos compositores de então (DOTTORI, 1992, p.53).

No mesmo sentido, André da Silva Gomes (1752-1844), contemporâneo de Dias de Oliveira, enuncia que os compositores da época observavam, estudavam e imitavam os ótimos tratados dos sábios mestres, além de fundamentarem-se nos preceitos próprios das Faculdades Retórica e Poética (SILVA GOMES) ${ }^{5}$, apud DUPRAT et al., 1998, p.179-180).

Seguidor dessa prática, Manoel Dias de Oliveira (1734/5-1813) expressa a utilização de semelhantes artifícios, o que pode ser verificado, por exemplo, no Moteto dos Passos em $O$ vos omnes:

\footnotetext{
${ }^{3}$ Aristóteles (384 a.C.-322 a.C.), Marco Túlio Cícero (106 a.C.-43 a.C.), Marco Fábio Quintiliano (35-95); na Idade Média, Santo Agostinho (354-430), Santo Isidoro de Sevilha (570-636); na Renascença, Desidério Erasmo de Rotterdam (1469-1536), Philipp Melanchthon (1497-1560) e, por fim, no Barroco, Cipriano Soares (1524-1593), Emanuele Tesauro (1592-1675), Padre Antônio Vieira (1608-1697), entre outros (SOARES; MACHADO NETO; NOVAES, 2012, p.71).

${ }^{4}$ Ana Paixão expõe que essa prática de relacionar música, gramática, retórica e poética também pode ser localizada em quadros teórico-musicais de autores como Gioseffo Zarlino (1517-1590), Marin Mersenne (1588-1648), René Descartes (1596-1650), entre outros (PAIXÃO, 2008, p.32-35).

${ }^{5}$ Régis Duprat enfatiza que o tratado de André da Silva Gomes é apresentado em cópia escrita de 1830 por Jerônimo Pinto Rodrigues, sem referência precisa da data do exemplar original (DUPRAT et al., 1998, p.9).
} 
Em O vos omnes, de Manoel Dias de Oliveira, encontramos o mesmo tipo de baixo cromático utilizado para retratar uma situação de tristeza desesperada, que aparecera como ostinato no Lamento de Cassandra, da ópera Didone (1641), de Francesco Cavalli (1602-1676) ${ }^{4}$ [grifo nosso] (DOTTORI, 1992, apud RICCIARDI, 2000, p.28).

Não obstante, Maurício Dottori destaca o emprego da retórica por Manoel Dias de Oliveira, o qual pode ser evidenciado através das frequentes cadências, dos intervalos melódicos e harmônicos com suas possíveis combinações e progressões e, por fim, pela linha do contraponto somada à ênfase dos afetos (DOTTORI, 1992, p.53).

Embasados nessas afirmações, o presente trabalho apresenta a aplicação de elementos e figuras retóricas pelo compositor mineiro, demonstrando que esses recursos eram usados a serviço da persuasão e eloquência, os quais serão apresentados em alguns exemplos de suas obras, por meio de uma metodologia fundamentada em análises retórico-musicais, associadas ao texto sacro, harmonia e disposição do discurso musical.

\section{O padrão discursivo instituído por Mattheson}

Johann Mattheson, em seu tratado Der Vollkommene Capellmeister (1739), elaborou um padrão composicional fundamentado na disciplina retórica, de maneira a provocar no discurso musical a mesma eficácia persuasiva da arte da oratória. Respaldado pelos cânones clássicos, estabelece, através das Cinco Fases da Retórica, maior relação entre música e o discurso, evidenciada a seguir.

- Inventio - início do discurso onde são descobertas pelo orador as ideias e os argumentos que sustentarão a sua tese, podendo abranger o ato de criação, das ideias musicais, entre outros.

- Dispositio - onde são distribuídas e ordenadas as ideias e argumentos encontrados na Inventio.

- Elocutio - é associada ao estilo. Nela são efetuados os processos de tratamento e desenvolvimento de cada ideia, item e ornamentação, também denominada Decoratio ou Elaboratio por outros autores.

- Memoria - são os mecanismos e procedimentos usados para memorizar o discurso e, por extensão, a ordem operacional de cada uma das fases retóricas.

- Pronuntatio - pronunciamento do discurso. É a última fase do sistema retórico, igualmente conhecida como Actio ou ação (atuação). Diz respeito à performance, isto é, à interpretação perante a público (SOARES; MACHADO NETO; NOVAES, 2012, p.72).

Em relação à Dispositio, alguns autores, como Gallus Dressler, elaboraram uma versão simplificada em três partes (Exordium, Medium e Finis). Todavia, em consonância com os cânones clássicos, Mattheson dispõe deste modo:

- Exordium - início e introdução do discurso;

6 Tal mecanismo diligentemente trabalhado pelo compositor brasileiro, para descrever o afeto de angústia, languidez e lamúria, é representada entre os compassos 42 e 44, da referida peça, pela figura da Pathopoeia (pathos, paixão, carinho, poeia, apresentação, expressão) uma representação viva de um afeto intenso e veemente. Além disso, ela pode ser usada para expressar afeição melancólica ou triste (BARTEL, 1997, p.362). 
- Narratio - declaração ou narração dos fatos;

- Propositio ou Divisio - exemplificação da tese fundamental;

- Confutatio - refutação dos argumentos expostos, ou seja, uma oposição ao tema inicial ou principal;

- Confirmatio - confirmação da tese inicial;

- Peroratio - conclusão (BUELOW, 2001, p.261-262).

\section{Análise e Exemplos de Figuras Retórico-Musicais}

\subsection{Anaphora}

Athanasius Kircher expõe que "a Anaphora acontece quando uma passagem é usualmente repetida com ênfase" (BARTEL, 1997, p.188). Em outro trecho, Kircher revela que essa figura também pode ser empregada em uma repetição onde a afirmação melódica se dá com notas diferentes (BUELOW, 2001, p.264). No primeiro exemplo, nota-se sua utilização, na tonalidade Sol Maior, entre os compassos 1 e 4, onde cada voz repete enfaticamente a expressão Laudate Dominum (Louvai ao Senhor).

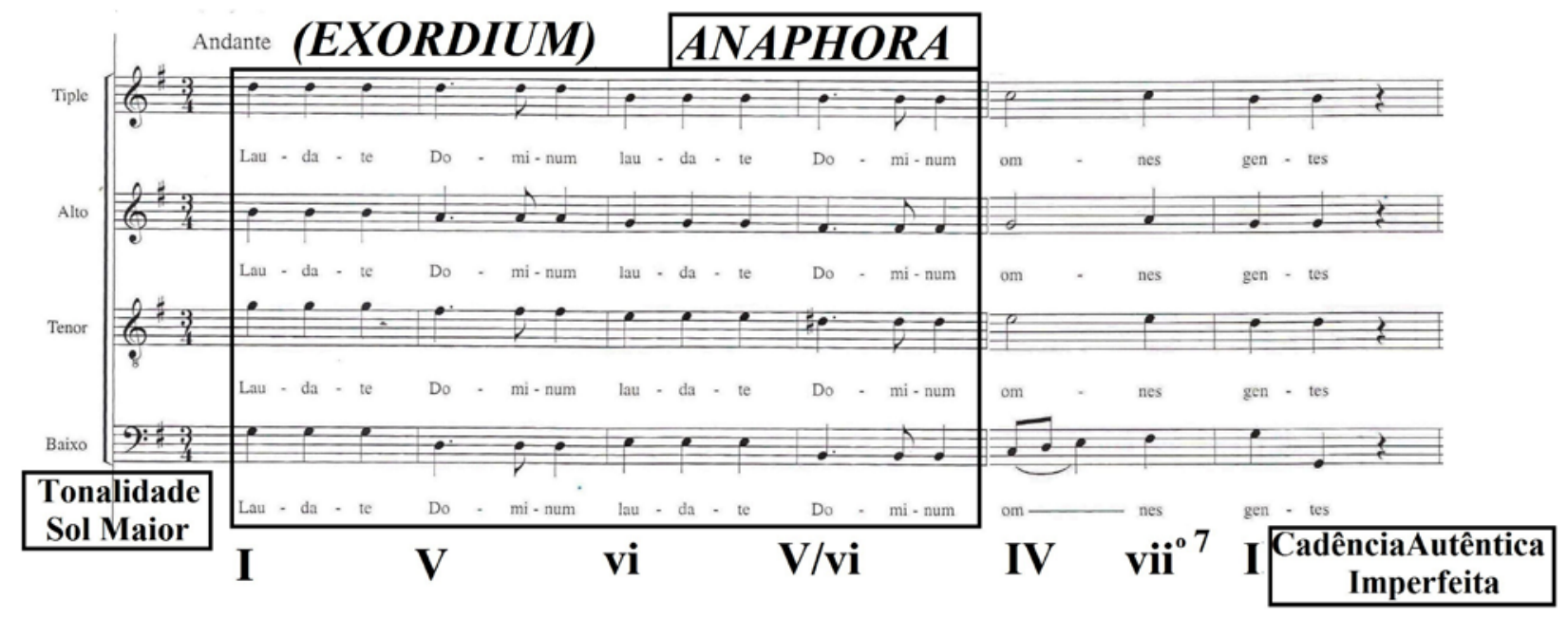

Ex.1: Anaphora no Laudade Dominum das Matinas e Vésperas de Sábado Santo de Manoel Dias de Oliveira- comp.1 a 4- Edição Maurício Dottori (OLIVEIRA, 2000, p.38-39).

A mesma figura é definida de maneira diferente por Joachim Thuringus (nascido em finais do século XVI), o qual afirma que "a Anaphora é a repetição continuada apenas no baixo" (BARTEL, 1997, p.188; BUELOW, 2001, p.264). No segundo exemplo, entre os compassos 3 e 8, verifica-se que há repetição contínua na voz do baixo como das palavras sibi crucem Jesus (Jesus carregou a cruz). Desse modo, examina- se a utilidade da Anaphora enfatizando o afeto de pesar, acompanhado de lamento e angústia.

Semelhantemente, percebe-se que esse sentimento é trabalhado por Dias de Oliveira nos diálogos entre as funções harmônicas da Tônica e Dominante. 


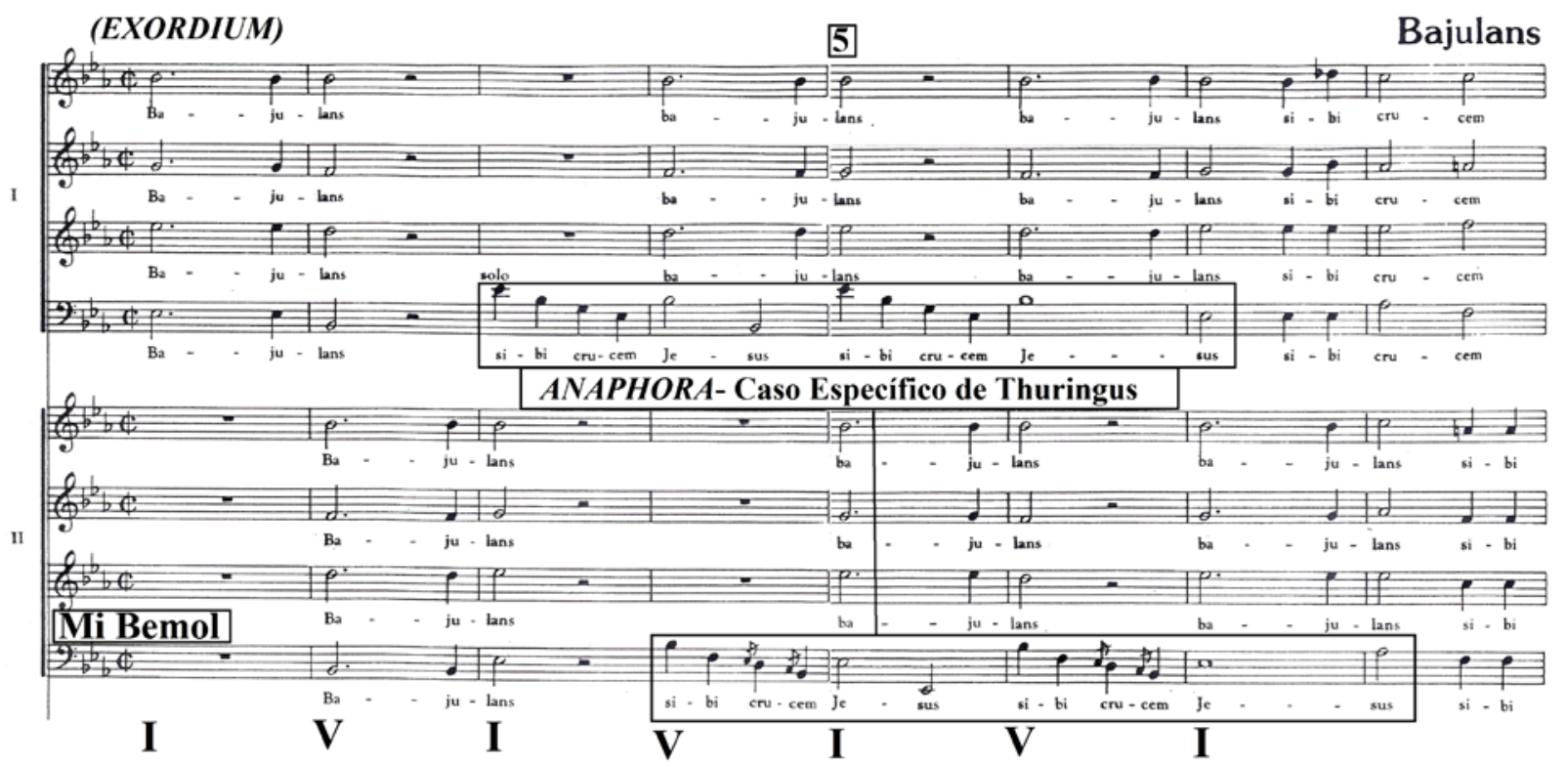

Ex.2 Anaphora no Bajulans do Moteto dos Passos de Manoel Dias de Oliveira- comp.3 a 8- Restauração Maurício Dottori (OLIVEIRA, s/d, p. 15-16).

\subsection{Synaeresis}

No Laudate Dominum, além da Anaphora examinada nos quatro primeiros compassos, verifica-se, também, o emprego da Synaeresis, que, segundo Mauritius Johann Vogt (1669-1730), "ocorre quando duas notas são colocadas em uma sílaba ou duas sílabas são colocadas em uma nota" (BARTEL, 1997, p.397). De igual maneira, não passa despercebida a Cadência na Dominante (Semicadência), encerrando a segunda seção da peça no compasso 10.

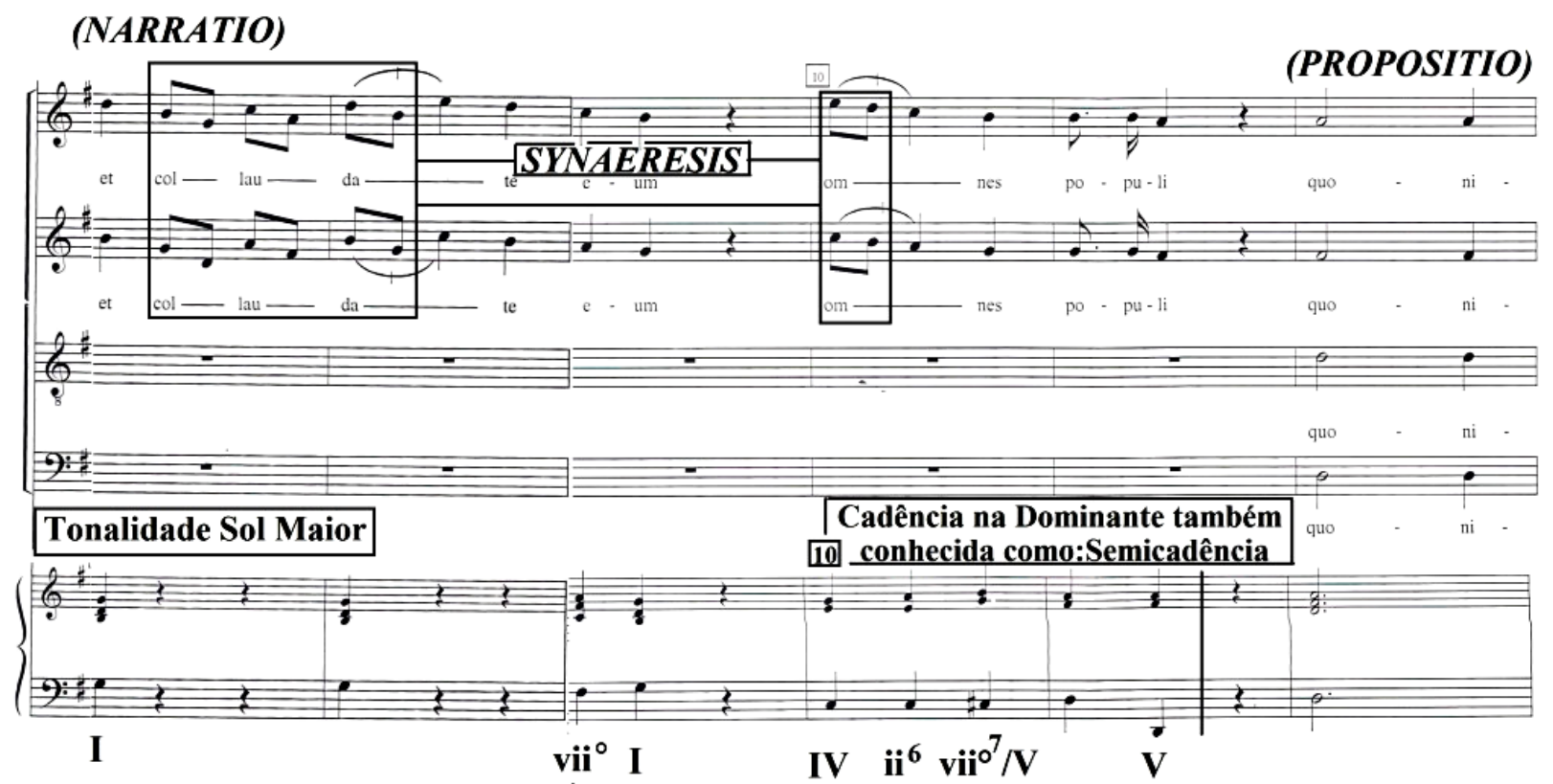

Ex.3: Synaeresis no Laudate Dominum das Matinas e Vésperas de Sábado Santo de Manoel Dias de Oliveira- comp.7 a 10 - Edição Maurício Dottori (OLIVEIRA, 2000 p.138-139). 


\subsection{Aposiopesis}

Johann Walther define a Aposiopesis como uma pausa generalis, a qual gera completo silêncio em todas as vozes simultaneamente (BARTEL, 1997, p.205). No Vinea Fact Est, das Matinas e Vésperas de Sábado Santo, de Manoel Dias de Oliveira, observa-se a ênfase gerada por essa figura valorando a Cadência Autêntica Imperfeita, na tonalidade de Dó Maior, após o momento de descanso nas quatro vozes entre a expressão et torcular, nos compassos 28 e 29, encerrando a terceira parte da Dispositio.

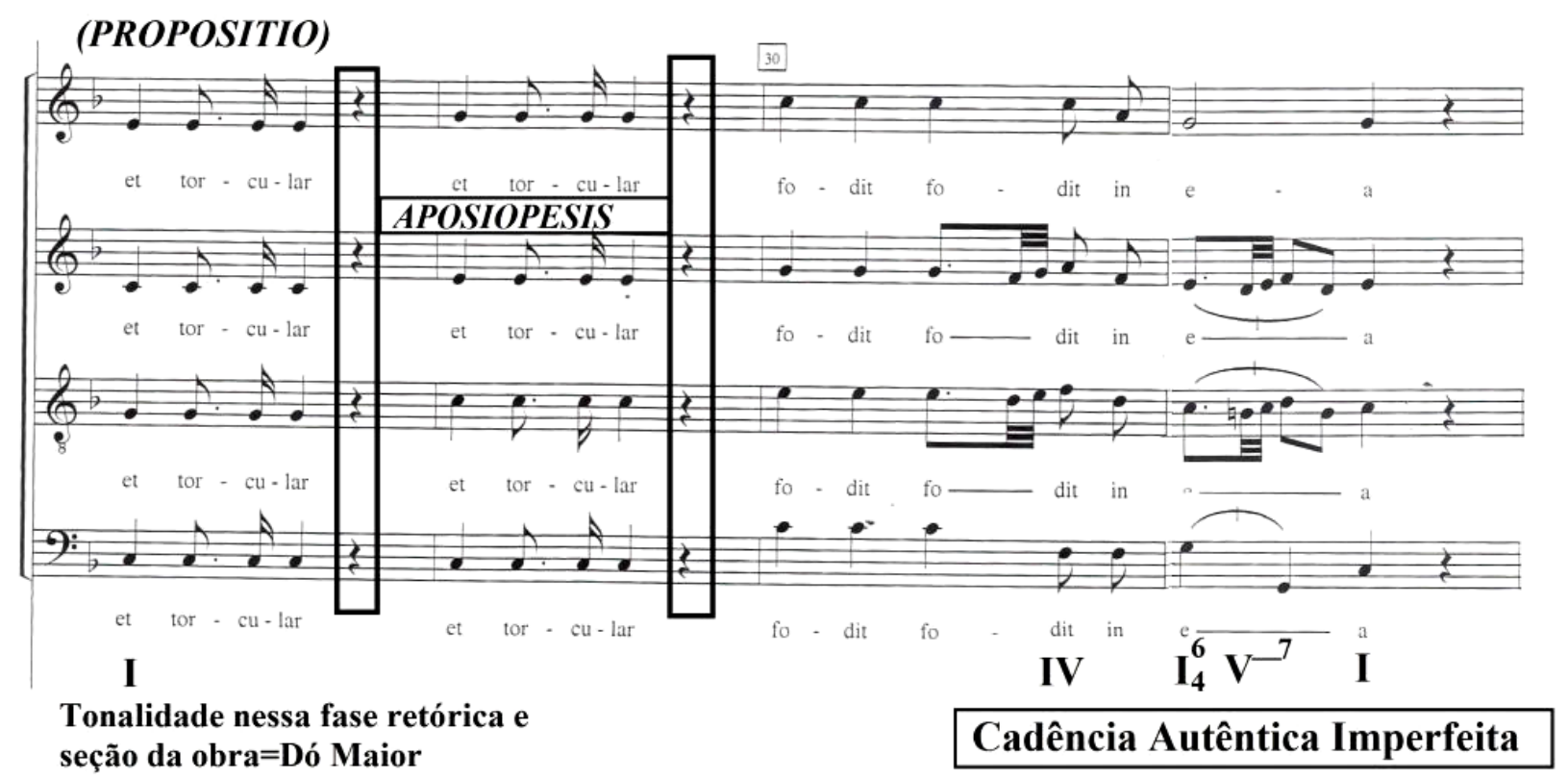

Ex.4: Aposiopesis no Vinea Fact Est das Matinas e Vésperas de Sábado Santo de Manoel Dias de Oliveira- comp.28 e 29- Edição Maurício Dottori (OLIVEIRA, 2000, p.60-61).

\subsection{Pausa}

A presente obra foi escrita para oito vozes, tendo seu texto extraído do sexto capitulo de Miqueias (Mq. 6: 3-4):

Popule meus, quid feci tibi? aut in quo contristavi te? Responde mihi. Quia eduxi te de terra Aegypti, parasti crucem Salvatori tuo.

Povo meu, que te fiz eu? Ou em que te contristei? Porque te fiz sair (te tirei) da terra do Egito, preparaste uma cruz para teu Salvador (ALMEIDA, 2000, p.10501051).

No primeiro e segundo compassos, examina-se a utilização da Pausa que, de acordo com Joachim Thuringus, "É um sinal de silêncio, cuja duração é designada de acordo com uma determinada nota" (BARTEL, 1997, p. 364). E por Walther, o qual afirma que essa figura: "É um período de repouso ou o silêncio na música, que é indicado por um determinado sinal" (BARTEL, 1997, p.365).

Outro aspecto relevante a ser verificado nesse excerto é a aplicação desse recurso retórico no tratamento de caráter responsorial, através do repouso dado às partes, onde o primeiro coro entoa a primeira frase Popule meus, completada em seguida, pelo segundo coro no terceiro compasso. 


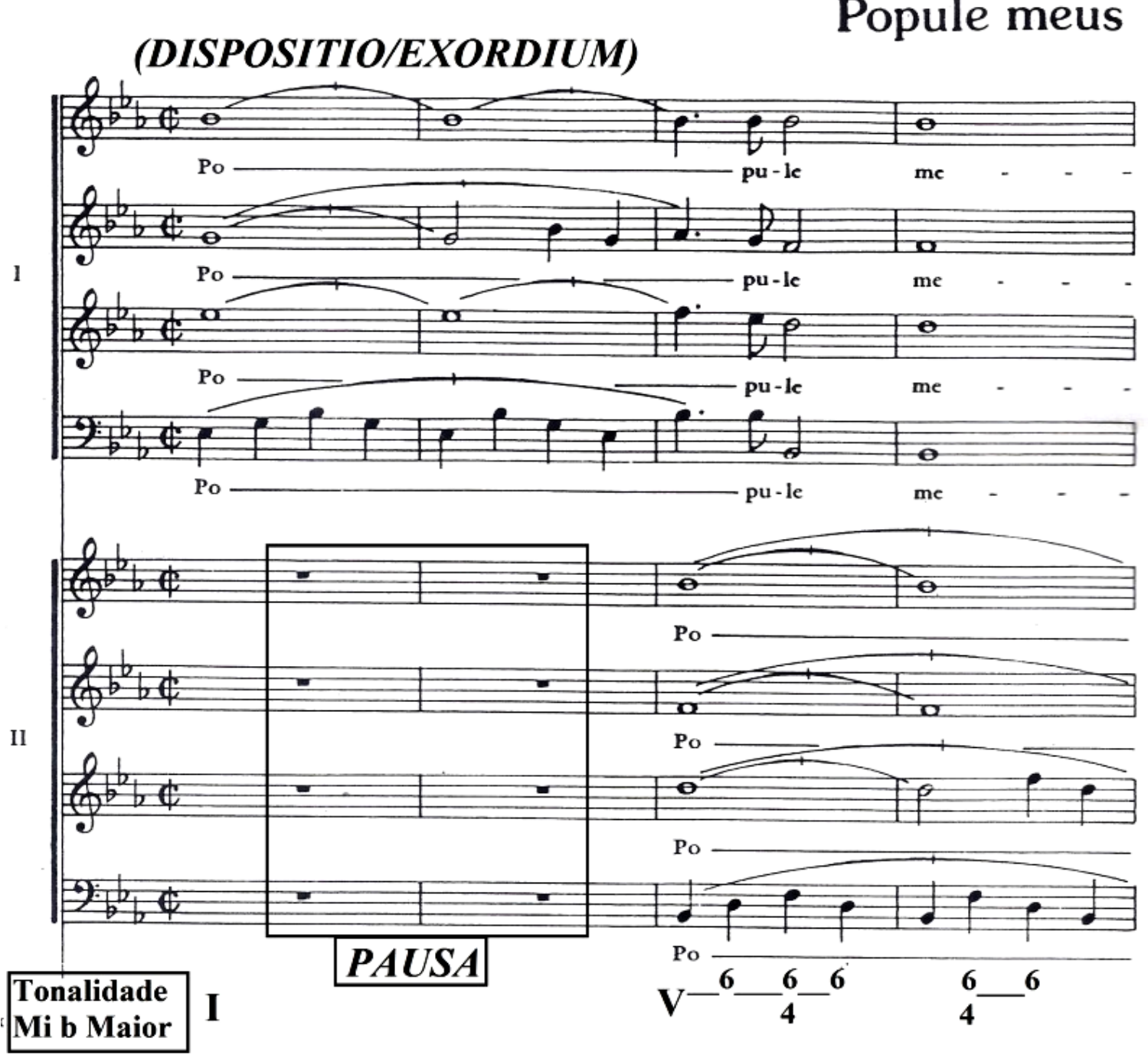

Ex. 5: Pausa no Popule meus do Moteto dos Passos de Manoel Dias de Oliveira- comp.1 e 2- Restauração Maurício Dottori (OLIVEIRA, s/d, p. 73).

\subsection{Analepsis}

Para Joachim Burmeister, a Analepsis "é uma repetição ou duplicação de uma Noema e, portanto, é um ornamento relacionado a ela" (BARTEL, 1997, p.184). Ainda no Popule meus, constata-se entre os compassos 17 e 21, nas vozes do contralto, tenor e baixo, o emprego da referida figura, repetindo literalmente a seção homofônica de uma Noem ${ }^{7}$ na mesma altura.

7 Passagem homofônica em uma textura contrapontística e polifônica (BARTEL, 1997, p.339). De igual modo, essa seção homofônica é utilizada para enfatizar o texto (BUELOW, 2001, p.268). 


\section{(NARRATIO dentro da PROPOSITIO)}

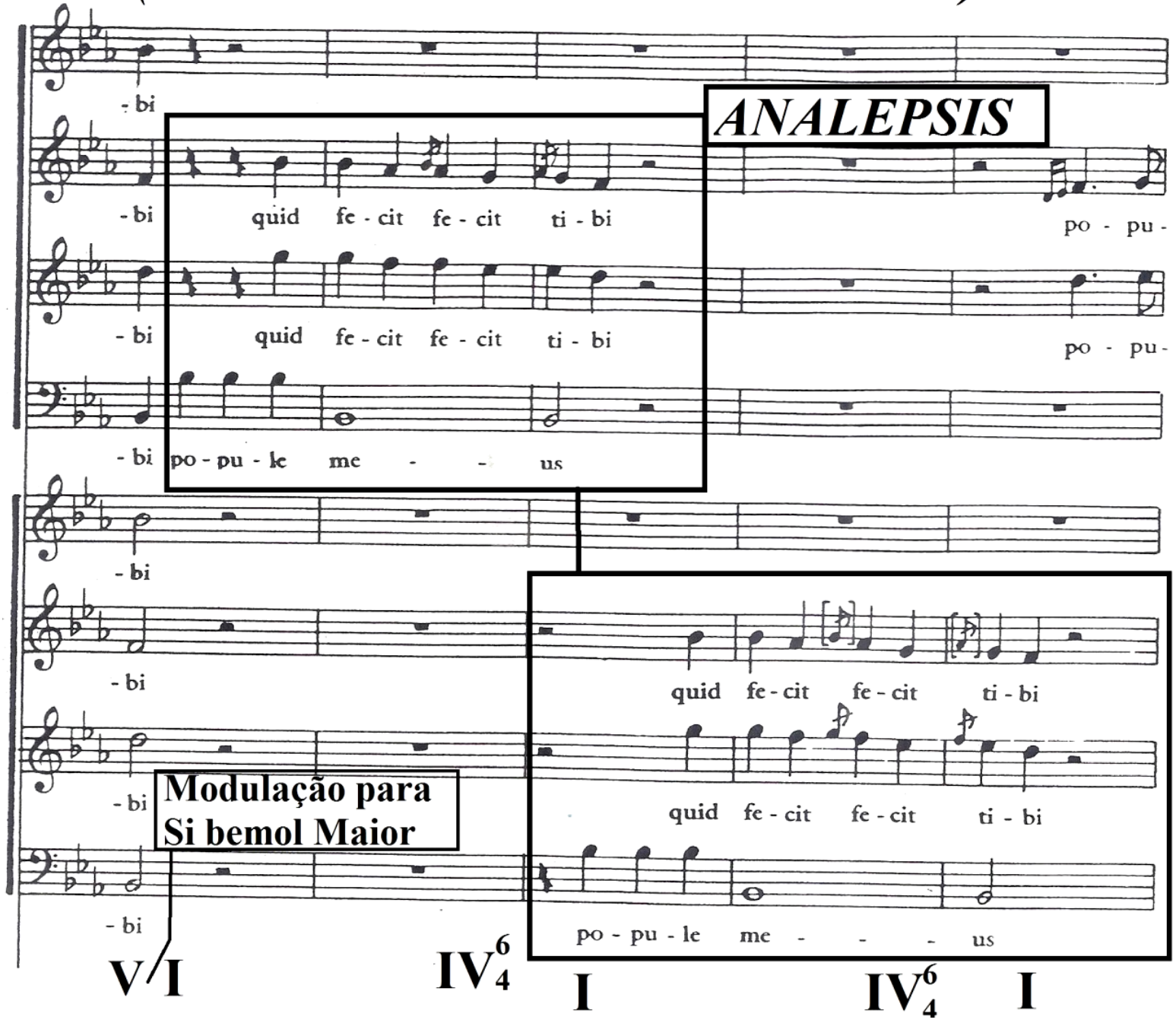

Ex.6: Analepsis no Popule meus do Moteto dos Passos de Manoel Dias de Oliveira- comp.17 a 21- Restauração Maurício Dottori (OLIVEIRA, s/d, p. 74).

\subsection{Variatio}

Ornamentação de uma passagem melódica com variedades de embelezamentos (BARTEL, 1997, p.432). Para Wolfgang Caspar Printz (1641-1717), a Variatio é empregada tanto para alterar determinada passagem melódica, por figuração, quanto em um trecho melódico da obra, porém, a ideia motívica inicial pode ser notada (BARTEL, 1997, p.435).

No Cantemus Domino das Matinas Vésperas de Sábado Santo, é observável que o autor faz a inserção dessa figura não só para variar os ornamentos, mas igualmente para enfatizar o enunciado, Gloriose emim honorificatus est (Porque gloriosamente manifestou seu poder), no solo da soprano e contralto, entre os compassos 24 e 28. 
(NARRATIO dentro da PROPOSITIO)

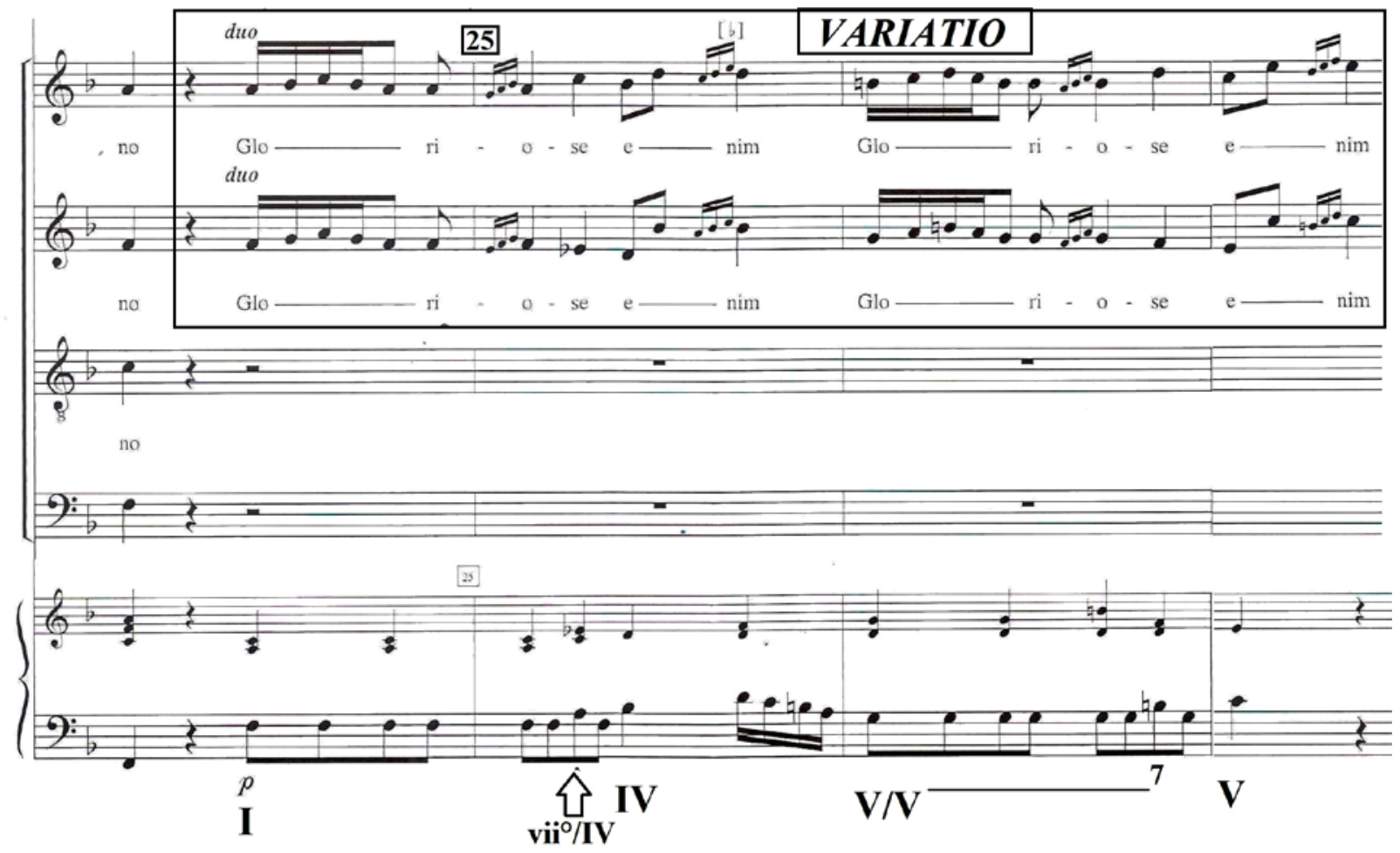

Ex.7: Variatio no Cantemus Domino das Matinas e Vésperas de Sábado Santo de Manoel Dias de Oliveira- comp.24 a 27-Edição Maurício Dottori (OLIVEIRA, 2000 p.27-28).

\subsection{Suspiratio}

Na mesma obra, verifica-se a aplicação da Suspiratio que, segundo, Kircher, "são os afetos naturalmente expressados por vários suspiros criados por meio de pausas" (BARTEL, 1997 p.393-394). Manoel Dias de Oliveira utiliza-se dessa figura para ressaltar a confirmação da tese inicial, baseada em Êxodo 15:1-3, a qual argumenta que todos devem louvar a Deus por que Ele gloriosamente manifestou seu poder, auxiliando e protegendo os hebreus, vencendo seus inimigos, através dos suspiros propiciados pelas pausas de semicolcheia entre as notas, no compasso 82 , na terceira repetição da expressão nomen est (seu nome).

Em síntese, os elementos retóricos usados pelo compositor também corroboram na valoração das funções harmônicas da Tônica, Subdominante e Dominante, dos motivos rítmicos, da fraseologia melódica e da Cadência Autêntica Perfeita. 


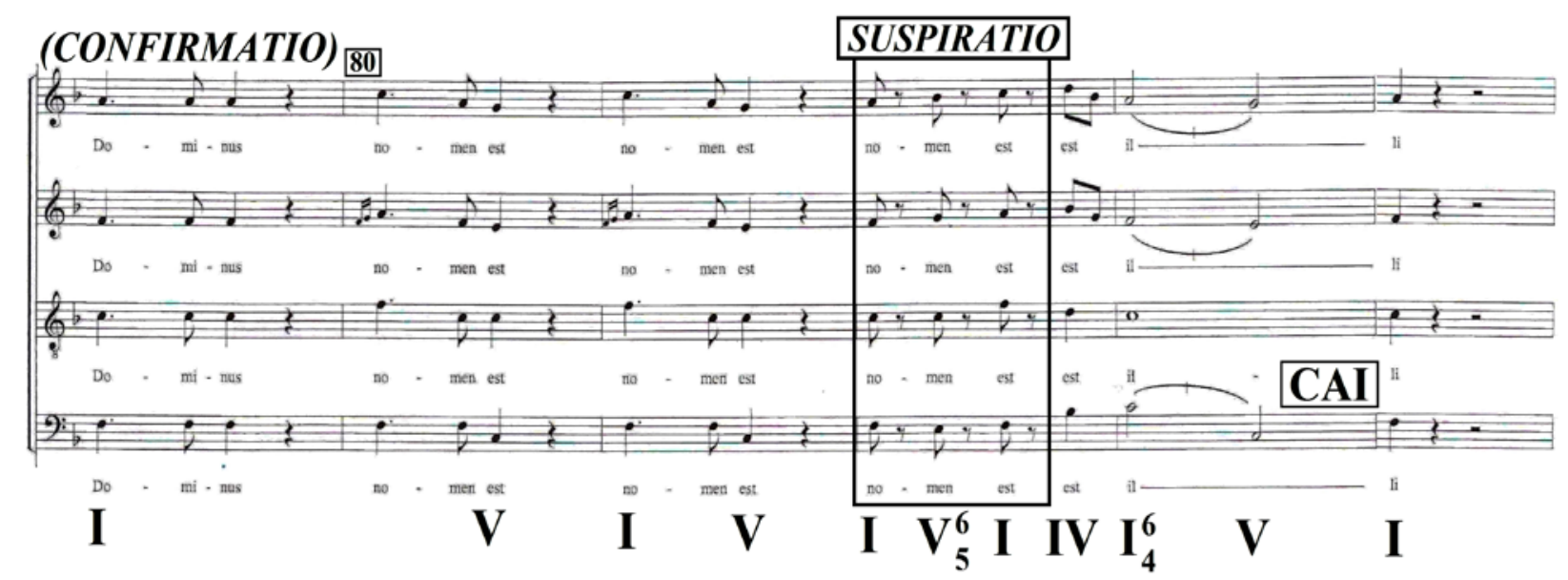

Ex.8: Suspiratio no Cantemus Domino das Matinas e Vésperas de Sábado Santo de Manoel Dias de Oliveira- comp. 82 -Edição Maurício Dottori (OLIVEIRA, 2000 p.45-47).

\subsection{Passus Duriusculus}

Trata-se de uma alteração cromática ascendente ou descendente de uma linha melódica (BARTEL, 1997, p.357). Christoph Bernhard (1628-1692) enfatiza que:

O Passus Duriusculus ocorre quando a voz sobe ou desce um semitom menor. Estas progressões alguns consideram como cromáticas, as razões pelas quais eles podem movimentar entre si. Também pode ocorrer quando o segundo grau é aumentado, uma terça é diminuída, ou a uma quarta ou quinta é aumentada ou diminuída (BARTEL, 1997, p.358).

Dias de Oliveira ordena esse moteto em sete partes, sendo examinada nesse exemplo, a terceira. O texto dessa parte se encontra em Hebreus 13:13: Exeamus ergo ad eum extra castra, improperium ejus portantes (Saímos, pois, ao seu encontro fora do acampamento, carregando a sua humilhação).

Tal passagem bíblica descreve o sofrimento de Jesus fora da porta da cidade (Jerusalém), o qual simbolizava não apenas a maldição que Ele levou sobre si, mas, igualmente, a sua rejeição da instituição religiosa dos judeus e seus respectivos líderes. Não obstante, é observável no excerto abaixo, o uso do Passus Duriusculus na voz do baixo- I, nos compassos 1 a 5, destacando esse momento de angústia e humilhação, além de despertar no ouvinte o afeto de desprazer e decepção. 


\section{Exeamus ergo ad Deum}

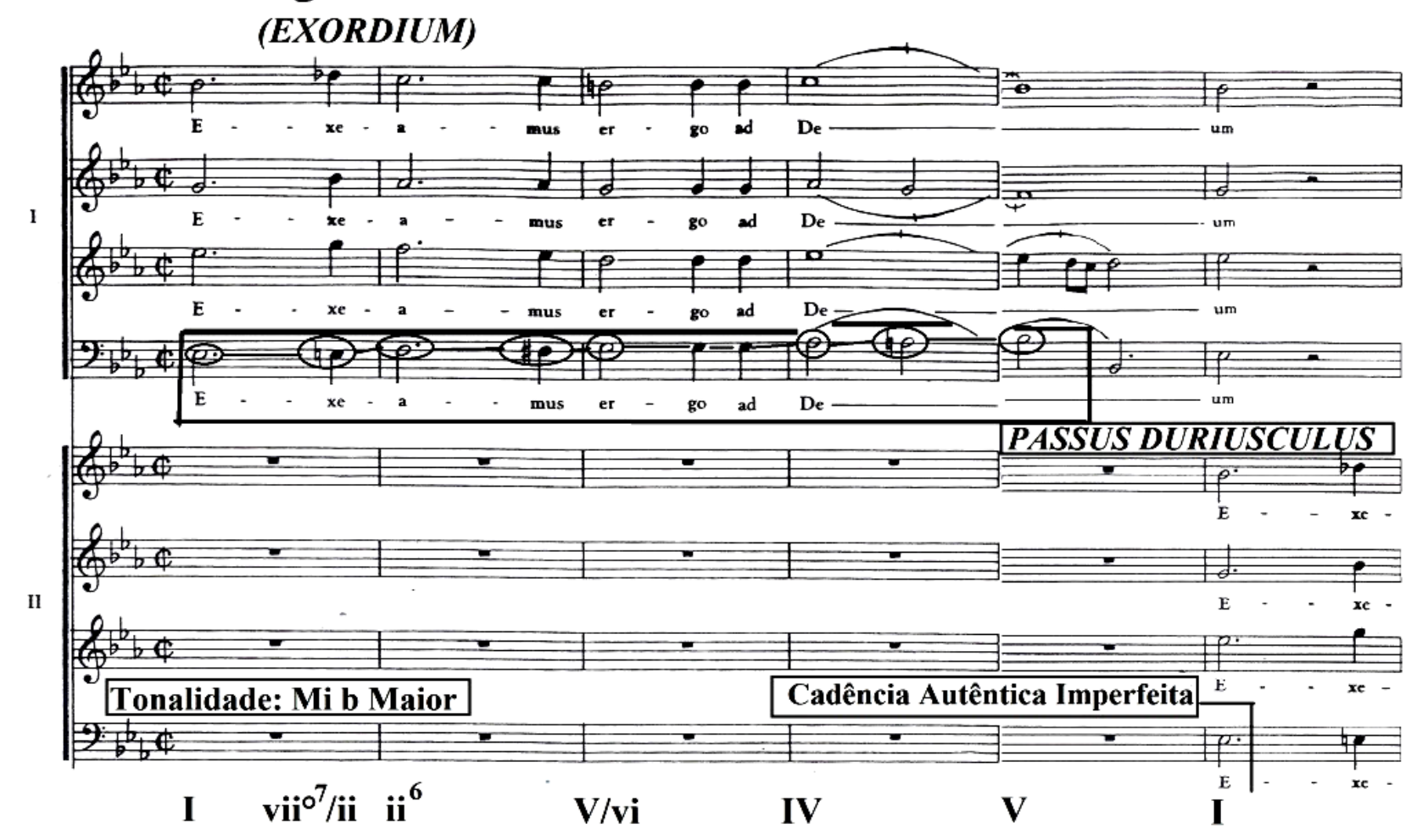

Ex.9: Passus Duriusculus no Exeamus ergo ad Deum do Moteto dos Passos de Manoel Dias de Oliveira- comp.1 a 5- Restauração Maurício Dottori (OLIVEIRA, s/d, p. 26-27).

\subsection{Epizeuxis}

Como sétima e última parte do Moteto dos Passos, O vos omnes retrata o sofrimento, humilhação e dor passados por Jesus durante o caminho percorrido, levando sua cruz até o momento de sua crucificação. Esse acontecimento há, aproximadamente, 586 anos antes de Cristo já havia sido descrito pelo profeta Jeremias em suas lamentações, dessa forma:

O vos omnes, qui transitis per viam, attendite et videte, si est dolor similis sicut dolor meus.

Não vos comove isto, a todos vós que passais pelo caminho? Considerai e vede se há dor igual à minha, que veio sobre mim, com o que o Senhor me afligiu no dia do furor da sua ira (ALMEIDA, [Lamentações de Jeremias 1: 12] 2000, p.920).

No excerto abaixo, pode ser observado o uso da Epizeuxis que, segundo Walther, "é uma figura de retórica pela qual uma ou mais palavras são imediatamente e enfaticamente repetidas" (BARTEL, 1997, p.265), entre os compassos 30 e 35, onde as expressões attendite e et videte, além dos motivos e notas, são repetidas para enfatizar o afeto de lamento e aflição. Essa condição igualmente se faz tangível nas funções harmônicas entre Tônica, Subdominante e Dominante, na transição da Confutatio para a Confirmatio, com terminação na Cadência Autêntica Perfeita. 


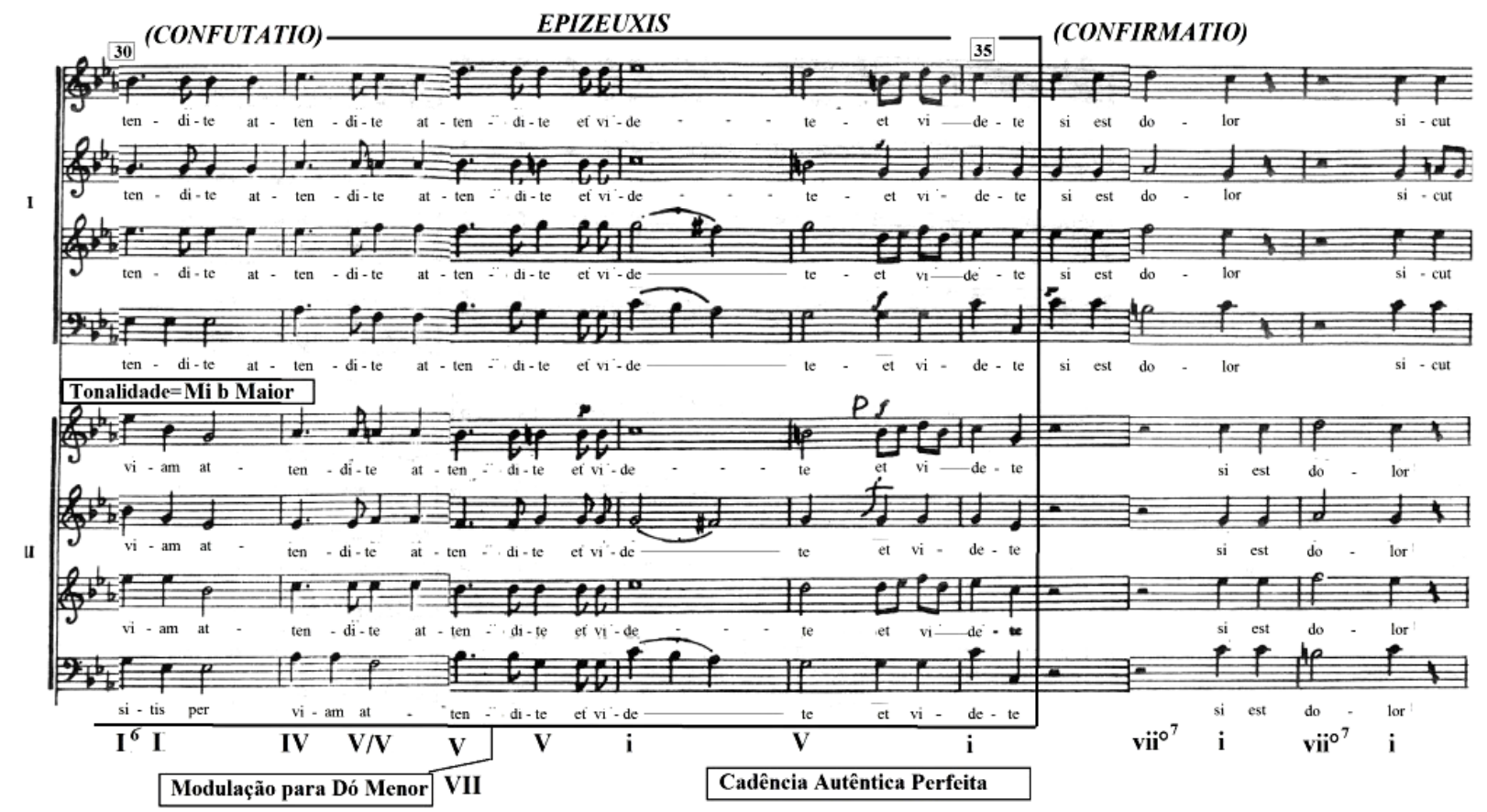

Ex.10: Epizeuxis no O vos omnes do Moteto dos Passos de Manoel Dias de Oliveira- comp.30 a 35- Restauração Maurício Dottori (OLIVEIRA, s/d, p. 44-45).

Observa-se, também, a mesma figura na conclusão do Kyrie da Missa Abreviada em Ré, onde as quatro vozes repetem de maneira enfática e efusiva a expressão eleison. Do mesmo modo, é verificável a utilização da dinâmica, reforçando tanto o destaque da linha fraseológica, das sílabas e notas como das funções da Tônica, Subdominante, Dominante e Tônica Paralela (Relativa), até sua resolução na Cadência Final (Autêntica Imperfeita).

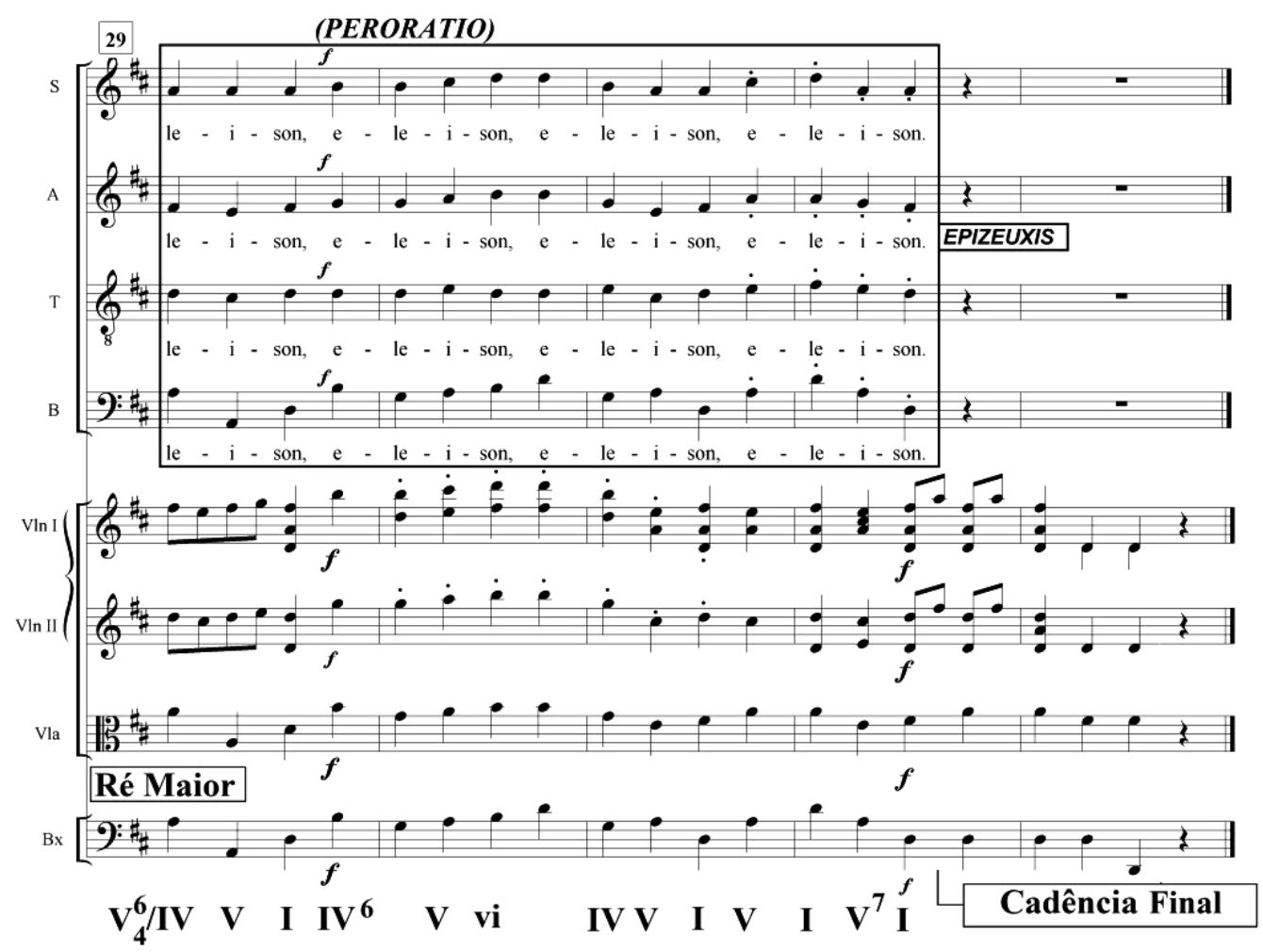

Ex.11: Epizeuxis no Kyrie da Missa Abreviada em Ré de Manoel Dias de Oliveira-comp. 29 a 32- Organização e Edição Paulo Castagna (CASTAGNA, 2002, p.4). 


\section{Considerações Finais}

O discurso musical, do segundo quartel do século XVI a princípios do XIX, era fundamentado em estruturas retóricas, cuja ordenação propiciava a eloquência. Semelhante ao orador, a finalidade do compositor era despertar no ouvinte suas paixões. Perito na arte da composição de músicas sacras, Manoel Dias de Oliveira demonstra sua habilidade no emprego de tais recursos em suas obras.

Ao averiguar os excertos das obras de Dias de Oliveira, notou-se a utilização de elementos retóricos, dispostos e ordenados, segundo a circunstância do discurso. Por exemplo, no Laudate Dominum, das Matinas e Vésperas de Sábado Santo, o compositor utiliza-se da Anaphora para enfatizar a expressão Laudate Dominum (Louvai ao Senhor), repetida duas vezes por todas as vozes, com o propósito de despertar no ouvinte $\mathrm{o}$ afeto de exultação. Em Bajulans, verificou-se que essa figura foi utilizada para destacar a linha melódica da voz do baixo, repetindo as palavras sibi crucem Jesus (Jesus carregou a cruz), objetivada em ressaltar para quem ouve o momento de tristeza e aflição passadas por Cristo. O terceiro exemplo, novamente na obra Laudate Dominum, constatou-se a Synaeresis, entoada pela soprano e tenor, entre os compassos 7 e 10, com duas notas para uma sílaba (pequenos melismas), enfatizando a palavra et collaudate (o louvai).

No Vinea Fact Est, o autor destaca o momento de silêncio e descanso em todas as vozes, através da Aposiopesis. No Popule meus do Moteto dos Passos, a Pausa é usada para valorar o diálogo estabelecido entre os dois coros, caracterizando, desse modo, o caráter responsorial da peça. De igual forma, na mesma obra, examinou-se o uso da Analepsis, onde as vozes do contralto, tenor e baixo repetem literalmente a seção homofônica de uma Noema na mesma altura.

Em Cantemus Domino, observou-se o emprego da Variatio, o qual ressaltou a expressão Gloriose enim (porque gloriosamente), através das variedades de suas ornamentações, seja das notas e dos ritmos. Não obstante, nessa peça é evidente a aplicação da Suspiratio, ressaltando as palavras nomen est (seu nome), produzindo um efeito sonoro como de suspiros, propiciado pelas pausas entre as notas, enfatizando o afeto de devoção, exaltando a Deus.

Por fim, há de se ressaltar mais duas figuras: o Passus Duriusculus e a Epizeuxis, a primeira empregada na peça Exeamus ergo ad Deum, evidenciando o momento de sofrimento e humilhação de Jesus ao carregar a cruz, através das progressões cromáticas na linha do baixo em semitons, já a segunda, utilizada na ênfase e repetição das palavras, motivos e notas, nas músicas $O$ vos omnes e no Kyrie, da Missa Abreviada em Ré.

Enfim, os exemplos analisados neste artigo são parte integrante de nossa pesquisa, ainda incipiente, sobre os estudos de retórica na música. O exame dessas figuras e elementos evidencia a competência do compositor na elaboração e disposição do discurso musical em suas obras, assim como a possibilidade da aplicação da retórica como ferramenta analítica para a compreensão dos processos composicionais na música colonial brasileira. 


\section{Agradecimentos}

Agradecemos à Fundação de Amparo à Pesquisa do Estado de São Paulo (FAPESP- Processo no 2013/23600-3) pelo apoio financeiro a esta pesquisa. 


\section{Referências:}

ABBAGNANO, Nicola. Dicionário de Filosofia. Tradução de Alfredo Bosi. 5a Edição Revista e Ampliada. São Paulo: Martins Fontes, 2007.

ALMEIDA, João Ferreira de. Bíblia de Estudo de Genebra. São Paulo: Editora Cultura Cristã (Sociedade Bíblica do Brasil), 2000.

Bíblia de Estudo Shedd. São Paulo: Edições Vida Nova Cultura Cristã (Sociedade Bíblica do Brasil), 2000.

BARTEL, Dietrich. Musica Poetica: Musical-Rhetorical Figures in German Baroque Music. Lincoln: University of Nebraska Press, 1997.

BUELOW, George. Rhetoric and Music. In: SADIE, Stanley., TYRRELL, John. (Org.), The New Grove Dictionary of Music and Musicians. New York: Oxford University Press Published, INC, 2001 vol. 21, p.260 - 275.

CASTAGNA, Paulo Augusto. (org.). Missa: Restauração e Difusão de Partituras. 1aㅗ Edição. Belo Horizonte: Fundação Cultural e Educacional da Arquidiocese de Mariana, vol. 2. 2002.

DOTTORI, Maurício. Ut Rhetorica Musica: análise do moteto O Vos Omnes a dois coros, de Manoel Dias de Oliveira. Revista Música, São Paulo, vol. 3, n. 1, p. 5369, 1992.

DUPRAT, Régis et al. A Arte Explicada de Contraponto de André da Silva Gomes. São Paulo: Arte \& Ciência, 1998.

GUIMARÃES, Elisa. Figuras de Retórica e Argumentação. In: MOSCA, Lineide do Lago Salvador. Retóricas de Ontem e de Hoje. 3a Edição. São Paulo: Associação Editorial Humanistas, 2004, p. 145-160.

OLIVEIRA, Manoel Dias de. Matinas e Vésperas de Sábado Santo. Edição de Maurício Dottori. São Paulo: EDUSP (Música Brasileira 2), 2000.

Moteto dos Passos. Restauração Maurício Dottori. São Paulo: s/d.

Partitura.

PAIXÃO, Ana Margarida Madeira Minhós. Retórica e Técnicas de Escrita Literárias e Musicais em Portugal entre os séculos XVII-XIX. 390 f. Tese (Doutorado em Literatura Comparada). Universidade de Lisboa em Co-Tutela na Univerisade de Nice, Lisboa, 2008. 
RICCIARDI, Rubens Russomano. Manoel Dias de Oliveira: Um compositor brasileiro em tempos coloniais-documentos e partituras. $142 \mathrm{f}+$ anexos. Tese (Doutorado em Artes)- Pós-Graduação em Música, Escola de Comunicações e Artes, ECA, Universidade de São Paulo, USP, São Paulo, 2000.

SOARES, Eliel Almeida; NOVAES, Ronaldo; MACHADO NETO, Diósnio. Retórica na Música Colonial Brasileira: o uso da Anaphora em André da Silva Gomes In: IV Encontro de Musicologia de Ribeirão Preto, 2012. Anais. Ribeirão Preto: LATEAM- Laboratório de Teoria e Análise Musicais, 2012. p. 301-306.

Análise Retórica em André da Silva Gomes: Exemplos de Figuras Retórico-Musicais. In: XXII Congresso da ANPPOM, 2012, João Pessoa-PB. Anais. Porto Alegre- RS: Editora da ANPPOM, 2012. p. 472-479.

Figuras Retóricas no Ofertório da Missa de Quarta-feira de Cinzas de André da Silva Gomes. Música Hodie, v. 12, n.2, p. 71-86, 2012. 